\title{
ESTRATÉGIAS DE URBANISMO SUSTENTÁVEL PARA LOTEAMENTO URBANO 1
}

\author{
Luciana Bernardes, Maria Alessandra Bacaro Boscoli
}

Universidade do Oeste Paulista - UNOESTE, Curso de Arquitetura e Urbanismo, Presidente Prudente, SP. E-mail: allyboscoli@gmail.com

\section{RESUMO}

O presente artigo aborda o conceito e princípios do urbanismo sustentável, como ferramenta para planejar assentamentos humanos que priorizem o bem-estar do usuário e o ambiente urbano. Identificamos ao longo da história um desenvolvimento urbano baseado no comportamento de consumo e um afastamento da qualidade de vida urbana. A urbanização dispersa, fruto da especulação imobiliária, foi possibilitada pela distância percorrida facilmente com o automóvel. A busca da qualidade urbana perdida, inicia com a reflexão do modelo de desenvolvimento econômico e os danos ao meio ambiente. O urbanismo sustentável apresenta uma nova forma de pensar os assentamentos urbanos, construído com prioridade ao pedestre, defendendo a cidade compacta em oposição à urbanização dispersa e a dependência dos automóveis. As ferramentas utilizada para alcançar uma urbanização sustentável esta firmada no aumento da densidade urbana, diferentes usos do solo, comércio local, espaços abertos, transporte integrado, controle de resíduos e edificações de alta eficiência.

Palavras - chave: Urbanismo sustentável; Loteamento urbano; qualidade ambiental urbana; bairro sustentável.

\section{SUSTAINABLE URBAN PLANNING STRATEGIES FOR URBAN DESIGN 1}

\begin{abstract}
This article discusses the concept and principles of sustainable urban design as a tool for planning human settlements that prioritize the user well-being and the urban environment. We identified throughout history urban development based on consumption patterns and a departure from the quality of urban life. The urban sprawl, the result of real estate speculation, was made possible by the distance easily navigated with the automobile. A search of the lost urban quality, starting with the reflection of the economic development model and the damage to the environment. Sustainable urban development introduces a new way of thinking about urban settlements, built with pedestrian priority to defending the compact city as opposed to urban sprawl and dependence on cars. The tools used to achieve sustainable urbanization this signed in increasing urban density, different land uses, local shops, open spaces, integrated transport, waste control and high efficiency buildings.

Keywords: Sustainable urban planning; Urban allotment ; urban environmental quality ; sustainable neighborhood.
\end{abstract}




\section{INTRODUÇÃO E OBJETIVOS}

O presente trabalho buscou um conceito que possa ser aplicado ao projeto de loteamentos urbanos, pesquisando importantes metodologias que tem como objetivo principal a qualidade físico-ambiental baseado nas percepções e vivências cotidianas da população.

Através das pesquisas entendemos as reais necessidades em repensarmos o ambiente construído a fim de superarmos os problemas urbanos e os impactos socioambientais decorrentes da expansão urbana e crescimento econômico sem o devido planejamento urbano.

O desenvolvimento urbano com foco na qualidade de vida urbana nos conduzem ao desenvolvimento sustentável associado ao desenho urbano de qualidade, planejamento e gestão democrática.

O conceito que chegamos como ideia geradora para nos conduzir ao bom projeto de loteamento, tem como fundamento os princípios dos movimentos do Novo Urbanismo, Crescimento Urbano Inteligente e Edificações Sustentáveis, sintetizado neste trabalho como Urbanismo Sustentável.

\section{METODOLOGIA}

A metodologia seguida foi baseada em levantamentos bibliográficos, buscando compreender os conceitos relativos ao tema abordado e a formulação de uma avaliação lógica da problemática, buscando qualificar atributos geradores de ambiente com boa qualidade de vida urbana.

\section{DESENVOLVIMENTO URBANO SUSTENTÁVEL}

Para pesquisarmos o tema proposto, primeiramente se faz necessário alinharmos o tema com o desafio de pensar a cidade na sua complexidade, como um ambiente construído pelas relações sociais, culturais, políticas e econômica que tão rapidamente ao longo da história se modificam e reconfiguram o espaço urbano.

O conceito de desenvolvimento econômico, dos países desenvolvidos, baseado na industrialização e na concentração de seus esforços para o crescimento do Produto Interno Bruto (PIB), deixou a qualidade de vida em segundo plano. O crescimento econômico era visto como meio e fim do desenvolvimento (OLIVEIRA,2002).

A sociedade abalada após a Segunda Guerra Mundial, passa expressar descontentamento, levando ao consenso que o progresso econômico não é capaz de gerar bem- estar social. Surge em 1941, a primeira Declaração Inter-aliada, como na Carta do Atlântico, do mesmo ano, que 
expressavam o desejo de criar condições para que todos os homens possam desfrutar de seguridade econômica e social. Um importante documento que tange as questões de desenvolvimento é a Carta das Nações Unidas (1945), cuja finalidade primava pela manutenção e melhoramento dos níveis de qualidade de vida.

Em 1968, inicia o questionamento do modelo econômico dos países industrializados liderado pelo Clube de Roma, debatendo os limites do crescimento, abordando temas como crescimento populacional mundial, industrialização, poluição, produção de alimentos e esgotamento de recursos (GAUZIN-MÜLLER, 2011).

A partir de 1972, encontros promovidos pela ONU (Organização das Nações Unidas) tem discutido sobre a busca de um caminho para o desenvolvimento que atenda às necessidades do presente sem comprometer a capacidade de as gerações futuras atenderem às suas próprias necessidades.

O planejamento urbano é essencial para orientar o futuro das cidades e bairros, quanto à aplicação do desenvolvimento urbano sustentável ao planejamento territorial e ao planejamento urbano, deve compreendido como um ideal de gestão e planejamento das cidades capaz de aliar o crescimento econômico à inclusão social e à proteção e preservação do meio ambiente, natural e construído, de modo a atender as necessidades das gerações presentes, sem comprometer os interesses e as necessidades das gerações futuras.

\subsection{Sustentabilidade e urbanismo}

A urbanização dispersa é considerada como causadora das mudanças climáticas, basta refletirmos sobre as normas de zoneamento e uso do solo que segregam o espaço urbano e forçam o deslocamento e a dependência do automóvel particular quando o sistema de transporte público não tem eficiência. (FARR, 2013)

O Urbanismo Sustentável representa uma mudança de postura no modo de ocupação do solo e infraestrutura, entendendo que estas são as estruturas fundamentais para sustentar o nosso modo de vida. Reconhecer os danos ambientais que afetam diretamente a saúde da população e o clima tanto na escala micro, meso e macro como consequência de um desenvolvimento urbano desordenado e dependente do automóvel, é o primeiro passo que nos conduz em direção ao Urbanismo Sustentável.

O processo que abriga a arquitetura e o urbanismo sustentável tem como objetivo o conforto ambiental (relação do ambiente e usuário), a conservação da energia e a utilização apropriada dos materiais e componentes das estruturas construídas, verificando seus efeitos 
através da análise do desempenho ambiental. Os espaços assim projetados são adequados ao lugar e concebidos segundo preceitos bioclimáticos.

O urbanismo sustentável deriva de três movimentos de reforma do final do século $X X$, os movimentos do Crescimento Urbano Inteligente, do Novo Urbanismo e das Construções Sustentáveis, e segundo FARR (2013) estes movimentos fornecem as bases filosóficas e práticas para o urbanismo sustentável.

O movimento do Crescimento Urbano Inteligente (Smart Growth) é considerado como a "consciência ambiental" do urbanismo sustentável. Inicialmente este movimento surgiu nos EUA, com ativista ambientalista em 1970 em meio à crise do combustível que colocou em cheque a dependência do automóvel pelos cidadãos, e mesmo a iluminação e energia produzida basicamente com o uso de carvão e outros materiais fósseis (GOLDEMBERG, 2010).

Em 1995 o governador do Colorado usou pela primeira vez o termo "Crescimento Urbano Inteligente" visão (Smart Growth), quando preocupado com a ocupação dispersa do seu estado propôs uma nova visão para regular a ocupação do solo. Em 1996, o então Movimento Crescimento Urbano Inteligente criou "os 10 princípios do crescimento urbano inteligente". Farr (2013, p.16) aborda os princípios.

1. Crie uma gama de oportunidades e escolhas de habitação

2. Crie bairros nos quais se possa caminhar

3. Estimule a colaboração da comunidade e dos envolvidos.

4. Promova lugares diferentes e interessantes com um forte senso de lugar.

5. Faça decisões de urbanização previsíveis, justas e econômicas.

6. Misture os usos do solo.

7. Preserve espaços abertos, áreas rurais e ambientes em situação crítica.

8. Proporcione uma variedade de escolhas de transporte.

9. Reforce e direcione a urbanização para comunidades existentes.

10. Tire proveito do projeto de construções compactas.

O Novo Urbanismo iniciou nos EUA, através de reuniões no ano de 1991, entre arquitetos ligados à Universidade Prince, que colaboravam para a elaboração dos Princípios Ahwahnee, conjunto de princípios comunitários para o planejamento do uso de terra, e também no projeto do Playa Vista - Califórnia, empreendimento de uso misto. Estes arquitetos defendiam a realização de Congressos como forma de combater a urbanização dispersa promovida pelo Congresso Internacional de Arquitetura Moderna (CIAM). O primeiro Congresso ocorreu em Alexandria, Virginia, em 1993.

Texto fundacional da Carta do Novo Urbanismo:

Nós defendemos a reestruturação das políticas públicas e práticas desenvolvimentistas que sustentem os seguinte princípios: as vizinhanças 
devem ser diversificadas em uso e população; devem ser projetadas para o pedestre como também para o carro; cidades grandes e pequenas devem ser conformadas por espaços públicos fisicamente definidos e universalmente acessíveis e por instituições de comunidade; os sítios urbanos devem ser moldados pela arquitetura do edifício e da paisagem, que celebram a história local, o clima, a ecologia, e a prática de edifício.

A Carta do Novo Urbanismo, de 1996, é o documento de referência do Congresso do Novo Urbanismo. A Carta estabelece princípios associados à formação do espaço regional, da cidade, e do bairro, com a intenção de: organizar sistemas regionais articulando áreas urbanizadas centrais com as cidades menores em setores bem delimitados do território, evitando a ocupação dispersa; valorizar a acessibilidade por transportes coletivos; favorecer a superposição de uso do solo como forma de reduzir percursos e criar comunidades compactas; estimular o processo de participação comunitária, e retomar os tipos do urbanismo tradicional relativos ao arranjo das quadras e da arquitetura. (MACEDO, 2007)

O terceiro movimento que segundo FARR (2013.p.21-23) influenciou o Urbanismo Sustentável foi o Movimento de desempenho e certificação de edificações da sustentabilidade através do U.S. Green Building Council (USGBC).

Esse movimento surgiu após a crise do petróleo em 1970 que impulsionou a busca pela economia de energia em edificações com o uso da calefação solar e energia fotoelétrica. Esse movimento só ganhou apoio das políticas governamentais após a Cúpula da Terra do Rio de Janeiro de 1992.

\subsection{Princípios e valores do Urbanismo Sustentável}

Recorremos a FARR (2013), com o objetivo de definirmos Urbanismo Sustentável, seus princípios básicos, valores centrais e atributos como forma de conduzir o desenvolvimento do tema e entendermos o bairro como a unidade básica de um desenvolvimento urbano sustentável.

[...] o urbanismo sustentável é aquele com um bom sistema de transporte público e com possibilidade de deslocamento a pé integrado com edificações e infraestrutura de alto desempenho. A compacidade (densidade) e a biofilia (acesso à natureza) são valores centrais do urbanismo. [...] $O$ urbanismo sustentável enfatiza que o apelo pessoal e os benefícios sociais da vida no bairro - satisfazer necessidades diárias à pé - são maiores em bairros que integram cinco atributos: definição, compacidade, totalidade, conexão e biofilia. (FARR, 2013,p.28)

A densidade urbana é um tema central para o urbanismo sustentável. 
As baixas densidades e os usos segregados do solo na urbanização dispersa geram maiores deslocamentos dependentes do automóvel.

Os bairros densos, com diferentes tipos de habitação entre unifamiliares e multifamiliares, associado ao emprego de diferentes usos do solo com comércio local, promove além da vitalidade do bairro permitido pelo acesso a destinos à pé, também possibilita a sustentação de transporte público.

As críticas as altas densidades tem como referência as consequências de altas concentrações associadas a ideia de superlotação e insalubridade.

Jacobs (2014, p.230), tem uma abordagem muito interessante quando afirma que, "as densidades são muito baixas, ou muito altas, quando impedem a diversidade urbana, em vez de a promover. Essa falta de funcionalidade é a razão de serem muito baixas ou muito altas."

O adensamento habitacional no bairro, colabora na geração de menor impacto, quando ocorre o agrupamento de várias unidades habitacionais. São várias as vantagens de ordem ambiental e econômica, pois permite reduções tais como: de área ocupada; de superfície expostas de fachadas e coberturas; de quantidade de materiais utilizados; consumo de energia; e custo da construção.

Quanto à forma da edificação, a melhor opção seria a integração das unidades em volumes compactos, ou seja edifícios coletivos. A habitação semicoletiva, também conhecida como habitação intermediária, é uma opção entre a casa e a habitação coletiva. São linhas sobrepostas com unidades duplex.

As casas geminadas são alternativas para satisfazer o desejo de que prefere morar em casas.

A alta densidade em si é ferramenta de controle de urbanização dispersa, mas não é suficiente, para explicar se determinada forma urbana é compacta ou não, sem estar relacionada a outros critérios como a compacidade.

A compacidade é identificada através da relação entre uma área e o número de determinados elementos; sejam pessoas, serviços, habitações ou área construída (PONT e HAUPT, 2009 apud FREIRE, 2014).

O princípio da diversidade urbana, defendida por JACOBS (2014) como o único meio capaz de garantir a vitalidade urbana, é compartilhado pelo urbanismo sustentável como parâmetro na definição de bairro.

A diversidade urbana é compreendida nos diferentes usos do solo, diferentes tipos de habitação que atenda a diferentes rendas e idades diferentes de edificações. 
Na busca pelo bairro ideal, a teoria do urbanismo ortodoxa, produziu bairros voltados para si, na tentativa de atender as necessidades em comum de uma pequena população local isolamse, desconsiderando a vida em cidade.

Refletindo sobre a natureza das cidades contemporâneas e os empreendimentos urbanos isolados, que fragmentam o tecido urbano e desprezam a continuidade das vias, devemos entender que este modelo de urbanização caminha em direção contrária ao bem-estar coletivo.

\section{CONSIDERAÇÕES FINAIS}

O que deveria reger as diretrizes para todo e qualquer empreendimento imobiliário, identificado neste trabalho como objeto de estudo - Loteamento, deveria ser alcançar o bem estar social, observando os aspectos ambientais, econômicos, culturais e da saúde que envolvem o planejamento e projeto do empreendimento.

Este é o ponto central dos movimentos do Novo Urbanismo, Crescimento Urbano Inteligente (Smath Growth) e o Urbanismo Sustentável, a escala humana, em que as pessoas são os reais usuários dos espaços, e são essas as adequações que acabam por conformar os projetos destes empreendimentos.

Estes empreendimentos, adequados as diretrizes de projeto baseado na escala humana, são uma mescla de serviços e vias de locomoção, espaços compartilhados onde busca-se uma maior interação de classes sociais e estilos, tanto arquitetônicos como de comportamento, uma crítica aos condomínios fechados tão em alta, onde os usuários seguem um padrão pré-definido e acabam por isolar-se do resto da cidade.

O objetivo principal, a qualidade ambiental e qualidade de vida nestes empreendimentos são percebidos pelo senso de comunidade e apropriação dos espaços públicos de convivência, por meio do contato nas ruas e calçadas, estendendo para todas as atividades locais.

\section{REFERÊNCIAS}

DEL RIO, V. Introdução ao desenho urbano no processo de planejamento. São Paulo : Pini, 1990. $198 p$.

DEL RIO, V.; SIEMBIEDA, W. (Org.). Desenho urbano contemporâneo no Brasil. Rio de Janeiro: LTC, 2013. 285p.

DUANY, A; SPECK, J; LYDON, M. The smart growth manual. New York: McGraw-Hill, 2010. Artigo Sustainability: Science, Practice, \& Policy <http://sspp.proquest.com> Acessado em 20 de Março de 2015. 
FARR, D. Urbanismo sustentável: desenhando com a natureza/ Douglas Farr; tradução: Alexandre Salvaterra. Porto Alegre: Bookman, 2013. 326p.

FREIRE, R. A., 1987- Densidade e diversidade : as dimensões de compacidade urbana / Rodrigo Argenton Freire. - Campinas, SP : [s.n.], 2014.

GAUZIN-MÜLLER, D. Arquitetura Ecológica. São Paulo: Editora SENAC São Paulo, 2011. Tradução Celina Olga de Souza e Caroline Fretin de Freitas.

GOLDEMBERG, J. 4 - Energia e Desenvolvimento Sustentável - Série Sustentabilidade. Ed. Blucher, 2010. Disponível em < http://www.blucher.com.br/editor/amostra/05708.pdf > Acesso em: 31 de julho de 2014.

GREEN BUILDING COUNCIL BRASIL. Disponível em: http://iabsc.org.br/concursofatmafapesc/wpcontent/uploads/2012/08/16.00hMaria Carolina Fujihara.pdf.

JACOBS, J. Morte e vida de grandes cidades: Jane Jacobs; tradução: Carlos S. Mendes Rosa; revisão da tradução: Maria Estela Heider Cavalheiro; revisão técnica: Cheila Aparecida Gomes Bailão. Martins Fontes, 2011.

LYNCH, Kevin. A boa forma da cidade. Edições 70, 2007.

LYNCH, Kevin. A imagem da cidade. Tradução Jefferson Luiz Camargo. São Paulo: Martins, 2011.

MACEDO, A.C. A Carta do Novo Urbanismo norte-americano. Arquitextos, São Paulo, ano 07, n. 082.03, Vitruvius, mar. 2007 Disponível em: http://www.vitruvius.com.br/revistas/read/arquitextos/07.082/262 Acessado em 25 de Março de 2015. 15:20.

MASCARÓ, J. Loteamentos urbanos. Porto Alegre: Masquatro, 2005. 210p.

MASCARÓ, L.; MASCARÓ, J.J. Ambiência urbana. Masquatro Editora, 2009.

OLIVEIRA, G.B. Uma discussão sobre o conceito de desenvolvimento. Revista FAE, Curitiba, v. 5, no 2, p. 37-48, maio/agosto 2002 . 